\title{
The appropriate use of sodium phosphates oral solutions
}

\author{
Jonathan Love MD FRCPC
}

$\mathrm{T}$ he advisory from Health Canada (March 15 and March 18, 2002) (1) regarding important safety information for patients taking sodium phosphates oral solutions has raised many questions about the appropriate use of these products by endoscopists.

Most practitioners follow the regimen of $2 \times 45 \mathrm{~mL}$ of oral sodium phosphates solutions $12 \mathrm{~h}$ apart, as first described by Vanner et al (2). Many subsequent trials and millions of doses of clinical experience have confirmed the initial results; it is highly effective, well tolerated, inexpensive and safe when given to appropriately selected and properly instructed patients.

Reports of serious adverse events associated with the use of these bowel-cleansing agents warrant careful analysis. But the risks and benefits must be kept in perspective, as with all medications. Wholesale abandonment of a useful product is not in our patients' best interests.

The main concern of most endoscopists is that the recommended maximum total daily dose for any indication in adults is $45 \mathrm{~mL}$ of sodium phosphates oral solution in a $24 \mathrm{~h}$ period. This effectively makes a one-day prep impossible, thereby reducing patient compliance and convenience - two major advantages of this product.

The justification for this warning was statistically significant electrolyte shifts (hypocalcemia, hyperphosphatemia, hypernatremia, hypokalemia and acidosis) that are more likely to occur with more than one $45 \mathrm{~mL}$ dose per $24 \mathrm{~h}$.

A recent review of the literature by Hookey et al (3) concluded that most reported adverse events using sodium phosphates oral solutions were due to inappropriate dosing. Electrolyte balance is primarily maintained by the kidney. In patients with adequate renal function the sodium and phosphate that is absorbed following the administration of a sodium phosphates oral solution is simply filtered and excreted by the kidney.

Therefore, if more than $45 \mathrm{~mL}$ of the product is to be used in a $24 \mathrm{~h}$ period, it is advisable to obtain baseline electrolyte levels before administration, as the letter to physicians states (1), and to ensure sufficient fluid replacement during the prep.

It follows from this that patients with renal failure or congestive heart failure, infants, frail or elderly patients and those incapable of following instructions should not be prescribed this medication.

However, for normal healthy adults, the benefits far outweigh the risks (less than one in one million doses results in a serious adverse event). The superior cleansing action of sodium phosphates facilitates effective screening colonoscopies. Furthermore, superior patient acceptance of sodium phosphates commonly leads to completion of the appropriate cleansing regimen, which is critical to provide a clean field of view for the colonoscopist.

Confusion arises from the apparent contradiction in the letter from the manufacturers. The letter initially proscribes using more than two doses in $24 \mathrm{~h}$ and then states that if you do use the $2 \times 45 \mathrm{~mL}$ in $12 \mathrm{~h}$ regimen, electrolytes and renal function should be measured prior. The Food and Drug Administration letter from the United States (4) says:

"It would be reasonable to consider obtaining baseline and post-treatment sodium, potassium, chloride, bicarbonate, calcium, phosphate, blood urea nitrogen and creatinine values in people (especially those at increased risk) directed to take more than $45 \mathrm{~mL}$ of oral sodium phosphate in a 24 -hour period. This may enable physicians to avert serious electrolyte problems."

The Canadian letter to physicians should be viewed as a reminder of the real risks of complacency, but in appropriate circumstances the bowel-cleansing regimen described by Vanner et al is safe and effective and offers an alternative to patients. The denominator in the risk benefit ratio should not be forgotten, because compliance and adequate cleansing of the bowel for a proper examination may be life-saving.

\section{REFERENCES}

1. Health Canada. Oral sodium phosphates solutions: Electrolyte disturbances. <http://www.hc-sc.gc.ca/hpfb-dgpsa/tpd-dpt/fleetphospho-soda_e.html and http://www.hc-sc.gc.ca/hpfb-dgpsa/tpddpt/sodium_phosphates_e.html> (Version current at August 21, 2003)

2. Vanner SJ, MacDonald PH, Paterson WG, Prentice RS, DaCosta LR, Beck IT. A randomized prospective trial comparing oral sodium phosphate with standard polyethylene glycol-based lavage solution (Golytely) in the preparation of patients for colonoscopy. Am J Gastroenterol 1990;85:422-7.

3. Hookey LC, Depew WT, Vanner S. The safety profile of oral sodium phosphate for colonic cleansing before colonoscopy in adults. Gastrointest Endosc 2002;56:895-902.

4. US Food and Drug Administration. Food and drug administration science backgrounder: Safety of sodium phosphates oral solution. $<$ http://www.fda.gov/cder/drug/safety/ sodiumphospate.htm> (Version current at August 21, 2003) 


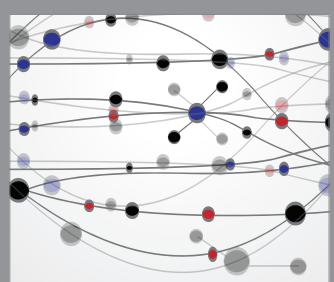

The Scientific World Journal
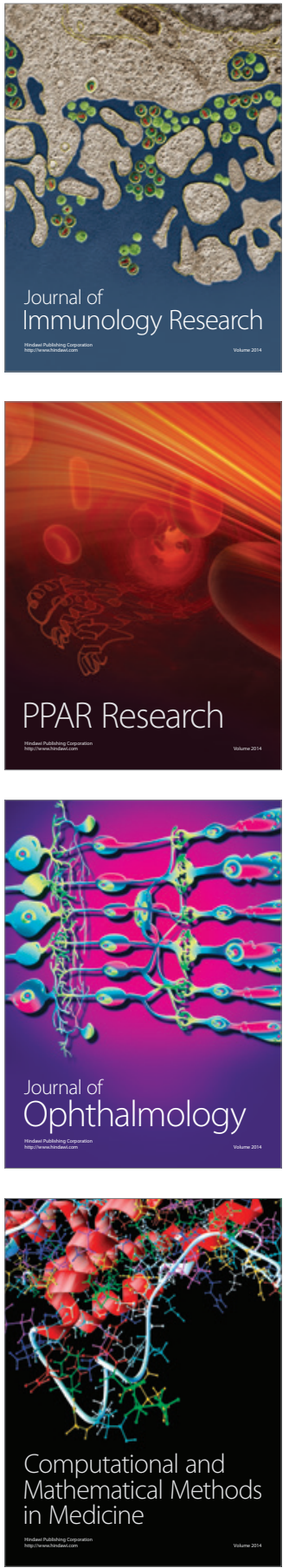

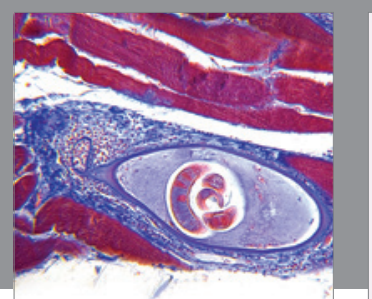

Gastroenterology Research and Practice

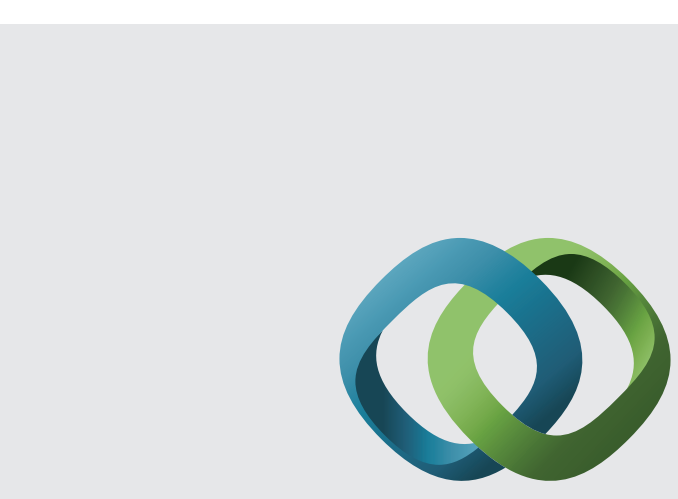

\section{Hindawi}

Submit your manuscripts at

http://www.hindawi.com
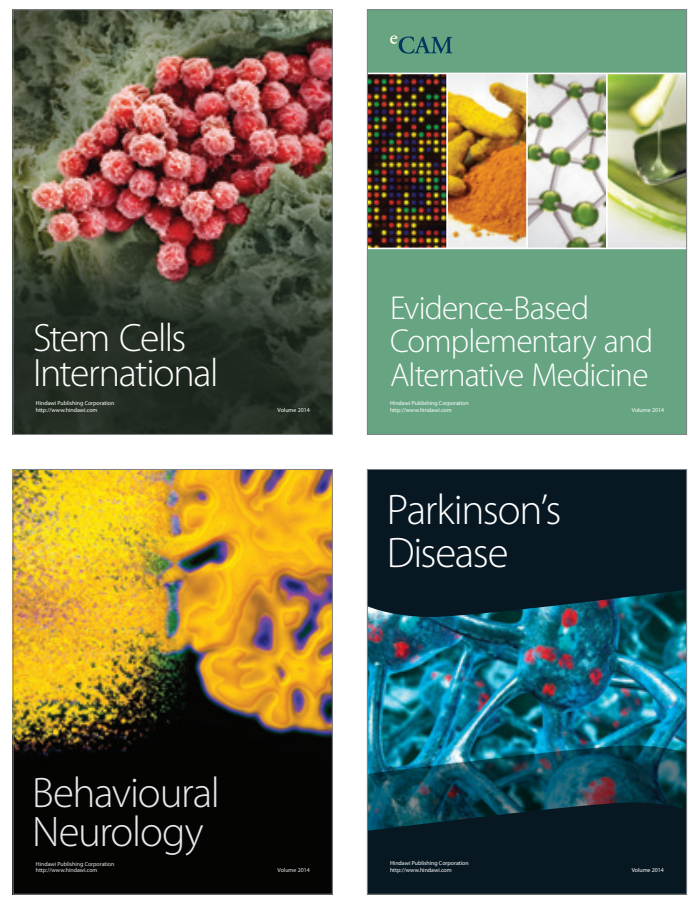
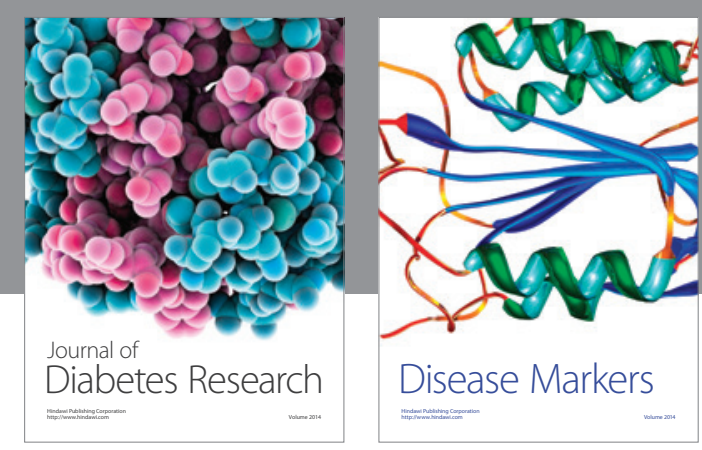

Disease Markers
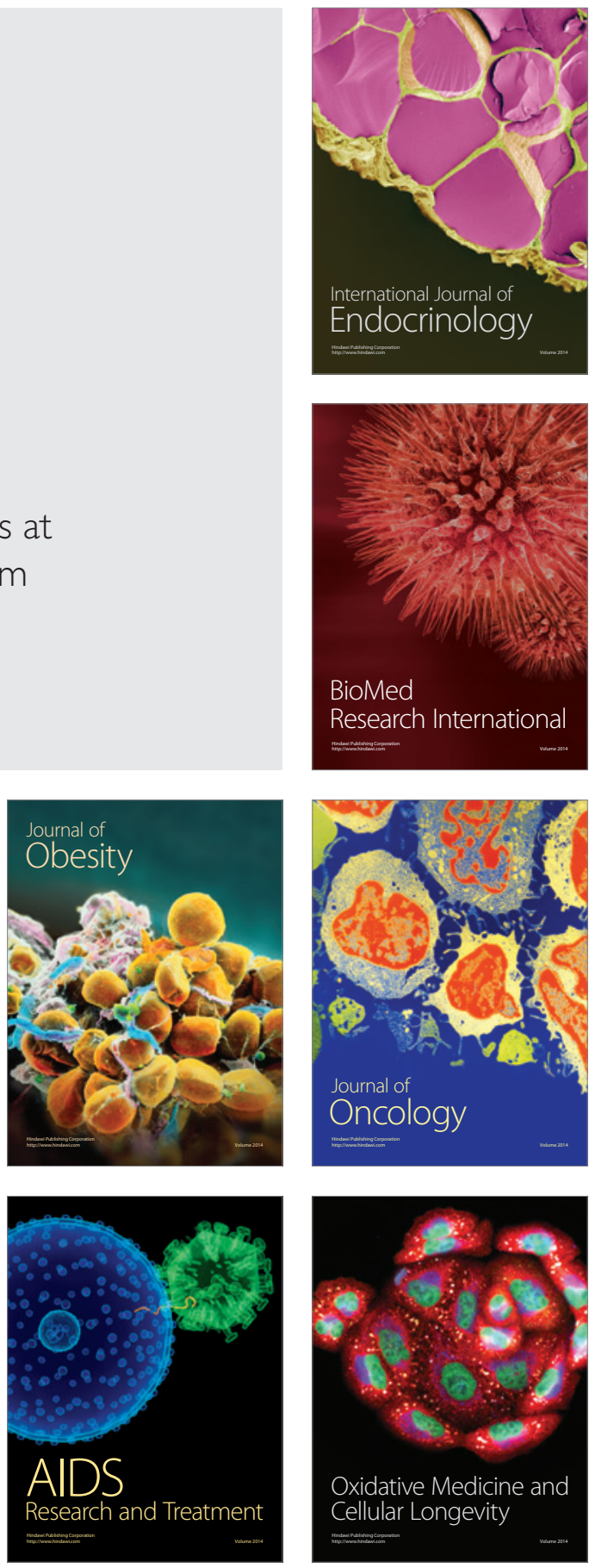